\title{
Adoption of technology on E-learning effectiveness
}

\author{
Zarina Denan, Zarina Abdul Munir, Rahayu A. Razak, Kardina Kamaruddin, \\ Veera Pandiyan Kaliani Sundram \\ Faculty of Business Management, Universiti Teknologi MARA Cawangan Selangor, Malaysia
}

\begin{abstract}
Article Info
ABSTRACT

Article history:

Received Aug 21, 2019

Revised Nov 14, 2019

Accepted Feb 28, 2020

\section{Keywords:}

Instructors characteristic

Learning effectiveness

Students' characteris tic

Technology

The incorporation of E-learning in both private and public tertiary education can help expedite the learning process. The utilization of fast-paced technology with E-learning also allows for a more flexible and convenient learning process. E-learning platforms can be accessed anywhere as long as there is an internet connection, including at home, the workplace, restaurants or while travelling. This allows for the benefit of distance learning. As such, the current study aims to examine the factor effectiveness of E-learning based on three variables, namely technology, instructors' characteristics and students' characteristics and their impact on distance learning. The education system has greatly evolved from the use of apparatus such as chalk and blackboards to the modern use of projectors to conduct lessons. In the current age, E-learning will have an effect on both instructors and teaching technology, aside from the students themselves. As an example, students are expected to know how to utilize these systems in their lessons, instructors must receive training in E-learning systems management and in terms of technology, the E-learning systems must be updated and operated using the most recent upgrades. E-learning is also cost-efficient, less time consuming and reduces the burden on both students and educators.
\end{abstract}

This is an open access article under the CC BY-SA license.

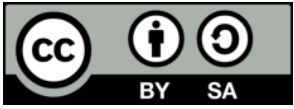

\section{Corresponding Author:}

Zarina Denan,

Faculty of Business Management,

Universiti Teknologi MARA Cawangan Selangor,

Kampus Puncak Alam, 42300 Bandar Puncak Alam, Selangor, Malaysia.

Email: ZarinaDenan2516@outlook.com

\section{INTRODUCTION}

The modern learning environment widely employs technology, specifically in the form of E-learning systems. E-learning is an electronic module that functions through the use of the student's computer, and thus does not require the direct presence of an instructor or teacher. E-learning exists for the benefit of internet-based education which can also be facilitated across distances. This form of learning requires plenty of active interaction in order to attract and engage students. Such elements include examinations, quizzes and other enrichment tasks. E-learning systems must be implemented and conducted within the parameters of established guidelines, due to the fact that this program does not utilize a facilitator to carry out the teaching process [1]. E-learning is an online educational system which allows for learning at any place or time. Initial E-learning formats employed a combination of various PC-centric functions such as compact disc programs. Modern E-learning however, is primarily conducted through the internet. E-learning systems use electronic media to facilitate these guidelines or preparation phases. However, such instructions only serve to highlight the accessibility of the resources as opposed to the expected outcomes or proven results of the system [2]. E-learning functions as a form of communication between students and teachers and a medium which requires mutual effort. It is also offered on an optional basis, with its foundation placed on the education field and the communications indus try. This is a tactic in order to evolve learning processes 
in the current global and modern context. The traditional "board and talk" method" of teaching where the educator conducts lectures and offers handouts with minimal interaction and engagement fro $\mathrm{m}$ students is no longer considered an effective learning or teaching processes.

The function of the E-learning module in adapting to current trends of knowledge acquisition is a suitable and necessary evolution in educational methods. Typically, higher level education involving college or university students will require improved and more productive methods to gain knowledge and foster ideas. This modern approach to seeking knowledge will encourage students and provide them with the necessary confidence in their own potential and achievements. E-learning must not be conflated with M-learning systems, which emphasize the utilization of internet-enabled devices such as tablets, laptops or mobile phones. E-learning on the other hand, is specifically constructed for PCs, web communication and the internet. The ability to exchange ideas, perspectives and data through the internet with multiple parties in a flexible manner allows for more impactful communication [1]. As such, the current study has the objective of ass essing the students' characteristics, instructors' characteristics and the technology, and their collective impact on the effectiveness of E-learning.

E-learning technology is accessible to students regardless of physical location or the presence of an instructor. E-learning is a viable alternative to traditional teaching environments where the lecturer and students occupy the same physical space. Research reveals that E-learning has an impact on students' academic outcomes. This can be seen in good assessment or examination results, as well as a general positive attitude from the students. This reflects the fact that good results and positive reviews are necessary in order to encourage the intention to utilize E-learning. Studies indicate that opinions regarding E-learning and intention are among the strongest factors which influence the actual usage of E-learning sustems. Attitudes also significantly impact intention, but the actual utilization of E-learning is what carries the most powerful effect on academic performance [3]. In the educational environment, students' characteristics are fostered through the encouragement gained in the learning process. Enhanced utilization of technology in this process will develop competency and motivate students to take more initiative, and this can result in more productivity. The compelling element of E-learning methods is the capacity for allowing students to acquire basic skills and competency with electronic devices, and for them to continue to take the initiative to learn more on their own. This provides a greater sense of fulfillment in learning. As such, educational institutions are encouraged to offer greater access to the relevant facilities and offer training regarding the proper ways to productively utilize this technology [4]. Aside from students, such learning or training is also essential for the instructors. In addition to the skillset they already possess, this will assist instructors in developing more creative teaching methods as well as more effective student evaluation systems.

Some researchers are of the opinion that training and skills are sufficient to sustain the effectiveness of E-learning. Students and lecturers with strong skills and training also make for excellent prospects in terms of future human resources [1,5]. In addition to cutting down on time spent, E-learning also simplifies the materials and resources necessary for teaching. This is due to the fact that various programs and gadgets already exist within the system and are accessible to participating students and instructors. Such resources reduce the burden of work for lecturers and also make things more convenient for long-distance students. These students can take it upon themselves to work independently with some guidance from instructors when necessary [6-16]. The method of instruction and the demographics of students have undergone tremendous change over time [7,9]. The approach to education and the resources available have markedly evolved in order to accommodate the varying needs, abilities and levels of accessibility of students and instructors. A notable element among the various changes that have occurred in this field is the growing role played by innovation in the context of training. Students utilizing information technology (IT) is also a reflection of how crucial the role of the internet has become in educational environments $[10-12,15]$. This can be used as evidence for the outcome of the studied variables in this research [5]. Based on the discussion ab ove, three hypotheses were constructed as follows:

a. Hypothesis 1: Instructors' characteristic is statistically significant to e-learning effectiveness.

b. Hypothesis 2: Students' characteristic is statistically significant to e-learning effectiveness.

c. Hypothesis 3 : Technology is statistically significant to e-learning effectiveness.

\section{METHODOLOGY}

A total of 181 undergraduate students in Human Resource Management were chosen from local universities to participate in a survey. This study incorporates 28 items used to distinguish and assess students' characteristics, instructors' characteristics, technology and E-learning effectiveness. These items were adapted from [6] and [4]. The interval scale was employed as a measurement to assess responses to the adapted questions and the degree to which the respondent agreed or disagreed with the statements given as outlined in Table 1. These are indicated on a four-point scale whereby 1-Strongly Disagree, 2-Disagree, 3-Agree and 4-Strongly Agree. The data collected was subjected to more analysis through partial least square (PLS) in order to distinguish the predictors of E-learning effectiveness. The results reveal that the dis tribution 
of gender was higher for females as compared to males. The number of female respondents encompass $70.0 \%(n=119)$ of total respondents while $30.0 \%(n=51)$ of respondents consist of males. As such, it can be seen that the vast majority of respondents in this study were dominated by female students. Most respondents are between the ages of 21 years old to 30 years old with the percentage of $68.2 \%(n=116)$. This is followed by respondents aged 31 years old to 40 years old with the percentage of $28.8 \%(n=49)$. While those aged above 40 years old constitute $2.9 \%(n=5)$ of all respondents. Most of the respondents utilize the computer for educational purposes for more than 5 hours, with the percentage being $43.5 \%(n=74)$. This is then followed by those who use the computer for learning for $2-4$ hours with the percentage of $32.9 \% \%(n=56)$, while usage between 1-2 Hours is $20.6 \%(n=35)$. Those who use the computer for educational purposes for under 1 hour is $2.9 \%(\mathrm{n}=5)$.

The reason for utilizing PLS in this research is in order to identify the causal structure proposed and to verify the hypothesis to the point where the respondents' data supports the established structure. The students' characteristics, instructors' characteristics and technology are all modeled as reflective constructs due to the fact that these variables are interchangeable, unidimensional and reliable to an identical degree. In other words, when one of the variables is removed from the model, the construct is not altered [7, 17]. In PLS, there exist measurements and structural models to evaluate the validity and reliability of constructs, as well as methods to test the hypothesis within the models. A measurement model evaluates construct measurement and the process of validation by examining composite reliability $(\mathrm{CR})$, average variance extracted (AVE) and discriminant validity. The combination of the results of these assessments create the measurement model. A set range of values must be acquired in order to establish high reliability and zero error in terms of discriminant issues. In terms of composite reliability, the threshold value must be higher than 0.5. The [8] analysis is utilized to assess discriminant validity, whereby the square root of AVE for every construct must be greater than its correlations with other constructs.

\section{RESULTS AND DISCUSSION}

Table 1 shows the convergent validity values which are made up of factor loadings of items, composite reliability and average variance extracted of E-learning effectiveness ( $\mathrm{CR}=0.912, \mathrm{AVE}=0.597)$, instructors' characteristics $(\mathrm{CR}=0.931, \mathrm{AVE}=0.662)$, students' characteristics $(\mathrm{CR}=0.875, \mathrm{AVE}=0.517)$ and technology $(\mathrm{CR}=0.899, \mathrm{AVE}=0.563)$.

Table 1. Convergent validity

\begin{tabular}{|c|c|c|c|}
\hline Variables & Factor loading & CR & AVE \\
\hline E-Learning effectiveness & & 0.912 & 0.597 \\
\hline E1: E-Learning will improve quality of education. & 0.717 & & \\
\hline E2: The E-Learning approach is better than the traditional approach. & 0.749 & & \\
\hline E3: The E-Learning approach is more enjoyable than the traditional approach. & 0.857 & & \\
\hline E4: E-Learning does not offer me any advantages. & 0.764 & & \\
\hline $\begin{array}{l}\text { E5: Communication with the in structor in the E-Learning en vironment was better than the } \\
\text { traditional environment }\end{array}$ & 0.806 & & \\
\hline E6: The E-Learning interface to be flexible to interact with learning. & 0.692 & & \\
\hline E7: My interaction with the E-Learning interface was clear and underst andable. & 0.808 & & \\
\hline Instructors characteristics & & 0.931 & 0.662 \\
\hline IC1: Instructors are friendly and approachable. & 0.785 & & \\
\hline IC2: Instructors are easily contacted. & 0.871 & & \\
\hline IC3: Instructors explain how to use the website at the beginning of the semester. & 0.589 & & \\
\hline IC4: Instructors encourage student interactions & 0.804 & & \\
\hline IC5: Instructors provide sufficient learning resources online. & 0.887 & & \\
\hline IC6: Instructors solve emerging problem efficiently. & 0.876 & & \\
\hline IC7: Instructors provide fast feedback to queries in the discussion forum. & 0.846 & & \\
\hline Student characteristic & & 0.875 & 0.517 \\
\hline SC1: I am anxious in completing my degree. & 0.785 & & \\
\hline SC2: I have belief in my capability to interact with technology. & 0.871 & & \\
\hline SC3: I am cognitively engaged in doing the E-Learning activities. & 0.589 & & \\
\hline SC4: I have the initiative and motivation to learn and use the system. & 0.804 & & \\
\hline SC5: I have high level of self - confidence in using the system. & 0.887 & & \\
\hline SC6: I am willing to participate in E - Learning activities. & 0.876 & & \\
\hline SC7: I am satisfied with time and place flexibility of the system. & 0.846 & & \\
\hline Technology & & 0.899 & 0.563 \\
\hline T1: The system allows easy access to information. & 0.824 & & \\
\hline T2: There is information credibility in the system. & 0.787 & & \\
\hline T3: The guidance screen is clear and easy to use. & 0.854 & & \\
\hline T 4: The IT infrastructure is reliable and secure. & 0.798 & & \\
\hline T5: There is adequate investment in infrastructure to support electronic performance. & 0.721 & & \\
\hline T6: I am rarely disconnected during online tutorial & 0.552 & & \\
\hline T7: I am satisfied with the browsing speed. & 0.671 & & \\
\hline
\end{tabular}


The results indicate that every item and construct within the model meet the threshold values of $\mathrm{CR}$ which are greater than 0.7 and with AVE greater than 0.5. The factor loading of the items tested were greater than 0.5 and suitable for use in the analysis. In terms of the measurement model, Table 2 depicts the outcome of [18-20] analysis and establishes that the discriminant is reached. As such it can be concluded that the main construct measures different aspects. Figure 1 shows the measurement model. As can be seen in this figure, the student characteristics, instruction characteristics and technology are the main parameters which affected e-learning effectiveness.

Table 2. Lerning results

\begin{tabular}{lcccc}
\hline \multicolumn{1}{c}{ Constructs } & 1 & 2 & 3 & 4 \\
\hline 1. E-learning effectiveness & 0.772 & & & \\
2. Instructors characteristics & 0.55 & 0.814 & & \\
3.Student characteristic & 0.753 & 0.499 & 0.719 & \\
4.Technology & 0.707 & 0.62 & 0.606 & 0.75 \\
\hline
\end{tabular}

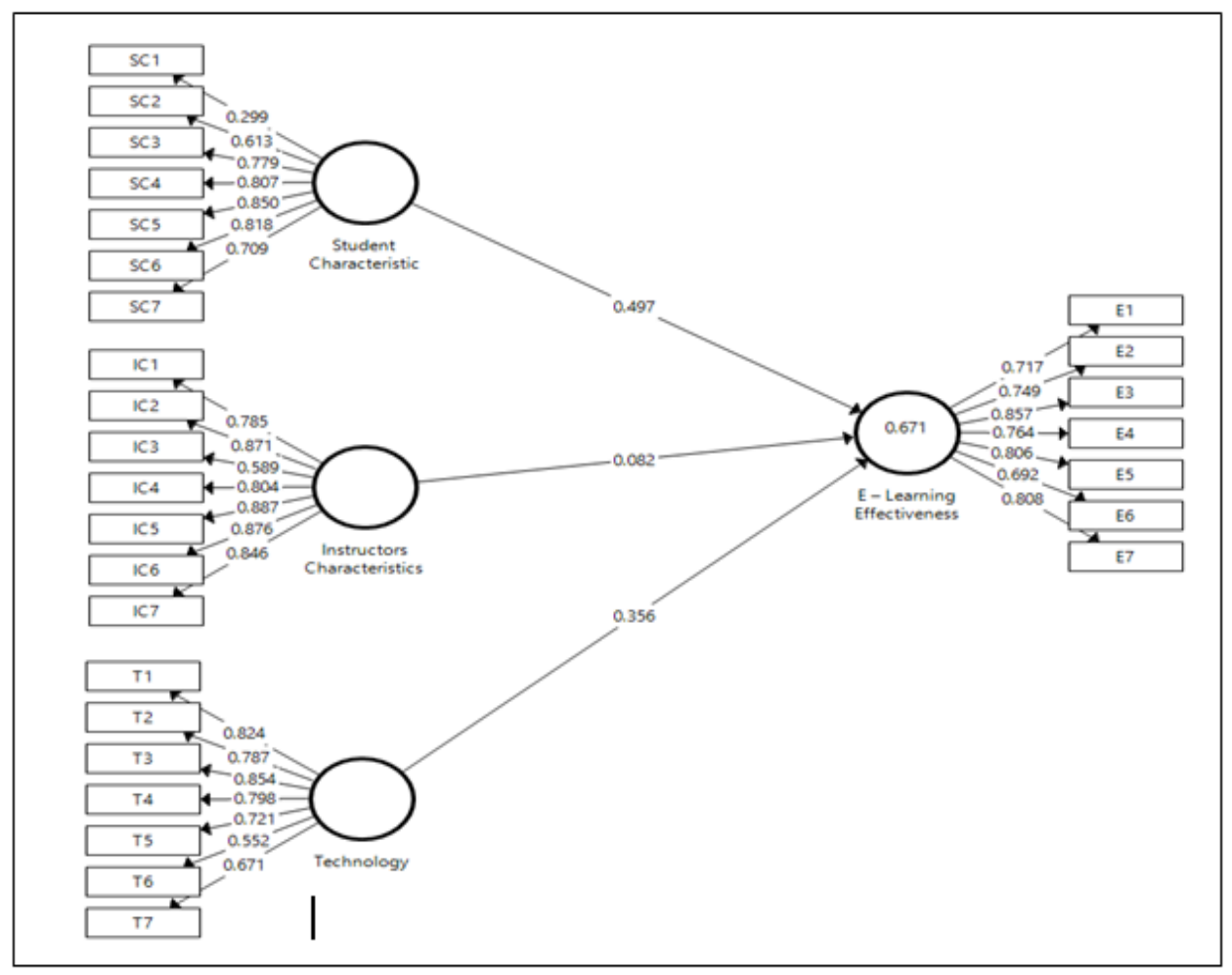

Figure 1. Measurement model

\subsection{Structural Model}

The structural model was assessed based on the significance of the structural path coefficient, the $\mathrm{R}$ square values $\left(\mathrm{R}^{2}\right)$ [21]. To test the significance, [22] suggest that the bootstrapping of 500 resamples be utilized to generate standard error (SE), t-statistic ( $t$-values) and the percentile of 95 percent confidence interval. The relationship between variables are indicated in Table 3.

Table 3. Relationship between variables

\begin{tabular}{lcccccccc}
\hline Relationship & Beta & STD & T-Values & P Values & LL & UL & \multirow{2}{*}{ Result } \\
\cline { 1 - 3 } $\begin{array}{l}\text { Instructors characteristics } \rightarrow \text { E-learning } \\
\text { effectiveness }\end{array}$ & 0.082 & 0.054 & 1.512 & 0.131 & -0.018 & 0.186 & $\begin{array}{c}\text { H1: Not } \\
\text { supported }\end{array}$ \\
$\begin{array}{l}\text { Student characteristic } \rightarrow \text { E-learning } \\
\begin{array}{l}\text { effectiveness } \\
\text { Technology } \rightarrow \text { E-learning effectiveness }\end{array}\end{array}$ & 0.497 & 0.06 & 8.342 & 0 & 0.375 & 0.594 & H2: Supported \\
\hline
\end{tabular}

Bulletin of Electr Eng \& Inf, Vol. 9, No. 3, June 2020 : 1121 - 1126 
The results in Table 3 indicate that the constructs achieve higher values of $\mathrm{R}^{2}$ with 0.671 than the substantial level indicated [23-25]. The two direct relationships which are students' characteristics $(\beta=0.497$, t-values $=8.342, \mathrm{p}<0.05)$ and technology $(\beta=0.356$, t-values $=4.323, \mathrm{p}<0.05)$ included in Figure 1 are statistically significant and accepted for instructors' characteristics $(\beta=0.082$, t-values $=1.512, p>0.05)$ As such, Hypothesis 2 and 3 were supported in this study. The significance estimated are obtained using a percentile bootstrap [26]. Results show that the lower limit and upper limit values do not contain zero, and explained how the direct effects are significantly different from zero with 95 percent confidence [23].

\section{CONCLUSION}

In the current study, three independent variables, namely Students' Characteristics, Instructors' Characteristics and Technology, were comparatively assessed against E-learning effectiveness. The collected data was analyzed using PLS statistics and the findings revealed that students' characteristics and technology influenced E-learning effectiveness, in contrast to the lack of support from the variable of instructors' characteristics. This study highlights the elements of attitude, motivation and behavior in the context of the role played by students and in the effective and productive use of E-learning.

\section{ACKNOWLEDGEMENT}

This research was supported by BESTARI Grant of Universiti Teknologi MARA, Malaysia (BESTARI 600-IRMI/SSP/DANA 5/3/BESTARI (00025/2016).

\section{REFERENCES}

[1] T. V. Paul, "An evaluation of the effectiveness of E-learning, mobile learning, and instructor-led training in organizational training and development," The Journal of Human Resource and Adult Learning, vol. 10, no. 2, pp. 1-13, 2014.

[2] P. Barodiya, A. S. Kushwah, and L. S. Kaurav, "A brief study of E-Learning: Special reference in education and corporate sector," International Journal of Advanced Scientific Research, vol. 1, no. 2, pp. 38-40, 2016.

[3] N. D. Oye, M. Salleh, N. A. Lahad, "Holistic E-learning in Nigerian Higher Education institutions," Journal of Computing, vol. 2, no. 11, pp. 20-26, 2010.

[4] B. L. C. Yiong, H. K. Sam, and T. K. Wah, "Acceptance of e-learning among distance learners: A Malay sian perspective," Proceedings Ascilite Melbourne, pp.541-551,2008.

[5] R. P. Bhatia, "Features and effectiveness of E-learning Tools," Global Journal of Business Management and Information Technology, vol. 1, no. 1, pp. 1-7, 2011.

[6] S. M. Al-Fadhli, "The impact of E-learning on student's critical thinking in higher education institutions Kuwait University as a case study," Thesis, University of Salford Manchester, 2008.

[7] K. Bollen and R. Lennox, "Conventional wisdom on measurement: a structural equation perspective," Psychological Bulletin, vol. 110, no. 2, pp. 305-314, 1991.

[8] C. Fornell and D. F. Larcker, "Structural equation models with unobservable variables and measurement error: Algebra and statistics," Journal of marketing research, vol. 18, no. 3, pp. 382-388, 1981.

[9] J. L. Roldán and M. J. Sánchez-Franco, "Variance-based structural equation modeling: guidelines for using partial least squares in information systems research," in M. Mora et al., (eds), Research Methodologies, Innovations and Philosophies in Software Systems Engineering and Information Systems, pp. 193-221, 2012.

[10] J. F. Hair, G. T. M. Hult, C. M. Ringle, and M. Sarstedt, "A primer on partial least squares structural equation modeling (PLS-SEM)," Sage Publications, 2016.

[11] W. W. Chin, "The partial least squares approach to structural equation modelling," in G. A. Marcoulides (Ed.), "Modern Methods for Business Research," Lawrence Erlbraum Associates Publishers, pp. 295-358, 1998.

[12] J. Williams and D. P. MacKinnon, "Resampling and distribution of the product methods for testing indirect effects in complex models," Structural Equation Modeling, vol. 15, no. 1, pp. 23-51, 2008.

[13] M. Nasiri, B. Minaei, and M. Rezghi, "Fuzzy dynamic tensor decomposition algorithm for recommender system," UCT Journal of Research in Science, Engineering and Technology, vol. 2, no. 2, pp. 52-55, 2014.

[14] S. Salehi and M. Mo'tadel, "Model presentation to feasibility measurement of knowledge management implementation with ANP approach (case study of Post bank)," Journal of Research in Science, Engineering and Technology, vol. 3, no. 4, pp. 17-23, 2015.

[15] J. J. Nirmal, N. J. Prabhu, and G. Sungunadevi, "A Study on knowledge, attitude and practices towards breast cancer among reproductive age group women in an urban area of Coimbatore," Indian Journal of Public Health Research \& Development, vol. 10, no. 7, pp.1332-1336, 2019.

[16] D. Madhumathi and S. Sakthi, "Evaluation of difference in bacterial contamination of toothbrushes between patients with gingivitis and patients with healthy gingiva-a pilot study," International Journal of Pharmacy Research \& Technology, vol. 9, no. 2, pp. 38-43, 2019. 
[17] M. Torquato, J. Araujo, I. M. Umesh, and P. Maciel, "SWARE: A methodology for software aging and rejuvenation experiments," Journal of Information Systems Engineering \& Management, vol. 3, no. 2, pp. 15-27, 2018.

[18] M. D. Farahani and H. Shahsavari, "GIS modeling of earthquake damage zones using ETM data and remote sensing-Bojnoord, Khorasan Province," UCT Journal of Research in Science, Engineering and Technology, vol. 1, no. 1, pp. 7-11, 2013.

[19] E. Zineb, B. Brahim, and A. Houdaifa, "The impact of SCRM strategies on supply chain resilience: A quantitative study in the Moroccan manufacturing industry," International Journal of Supply Chain management, vol. 6, no. 4, pp. 70-76, 2017.

[20] P. Pouladi, A. Afshar, M. H. Afshar, A. Mplajou, and H. Farahmand, "Agent-based socio-hydrological modeling for restoration of Urmia Lake: Application of theory of planned behavior," Journal of Hydrology, vol. 576, pp. 736-748. 2019

[21] N. A. Malik et al., "Investigation of lower limb's muscles activity during performance of salat between two age groups," Indonesian Journal of Electrical Engineering and Computer Science, vol. 14, no. 2, pp. 608-617, 2019.

[22] M. S. M. Gismalla and M. F. L. Abdullah, "Performance evaluation of optical attocells configuration in an indoor visible light communication," Indonesian Journal of Electrical Engineering and Computer Science, vol. 14, no. 2, pp. 668-676, 2019.

[23] H. Wang, H. Zhang, C. Song, and C. Xu, "The impact of HVDC links on transmission system collapse," Indonesian Journal of Electrical Engineering and Informatics, vol. 16, no. 1, pp. 21-31, 2018.

[24] S. K. Hildayanti and J. Alie, "Factors influenced paddy farmers to use or not use organic fertilizers in South Sumatera, Indonesia," Humanities \& Social Sciences Reviews, vol. 4, no. 1, pp. 53-58, 2016.

[25] M. Rizwan, M. Ahmed, and S. Gul, "Ideology and politics of Jamiat Ulema-i-Islam (1947-1973)," Global Social Sciences Review, vol. 3, no. 1, pp. 44-55, Mar 2018.

[26] S. Panigrahi and A. Thakur, "Modeling and simulation of three phases cascaded H-bridge grid-tied PV inverter," Bulletin of Electrical Engineering and Informatics, vol. 8, no. 1, pp 1-9, 2019. 